\title{
The Impact of Intrahospital Transports on Brain Tissue Metabolism in Patients with Acute Brain Injury
}

\author{
Jan Küchler ${ }^{*} \mathbb{D}$, Franziska Tronnier, Emma Smith, Jan Gliemroth, Volker M. Tronnier and Claudia Ditz
}

C 2018 Springer Science+Business Media, LLC, part of Springer Nature and Neurocritical Care Society

\begin{abstract}
Background: Patients with severe acute brain injury (ABI) often require intrahospital transports (IHTs) for repeated computed tomography (CT) scans. IHTs are associated with serious adverse events (AE) that might pose a risk for secondary brain injury. The goal of this study was to assess $\mathrm{HT}$-related alterations of cerebral metabolism in ABI patients.

Methods: We included mechanically ventilated patients with $\mathrm{ABI}$ who had continuous multimodality neuromonitoring during an 8-h period before and after routine IHT. Intracranial pressure (ICP), cerebral perfusion pressure (CPP), brain tissue oxygenation $\left(\mathrm{PtiO}_{2}\right)$ as well as cerebral and subcutaneous microdialysis parameters (lactate, pyruvate, glycerol, and glutamate) were recorded. Values were compared between an 8-h period before (pre-IHT) and after (post-IHT) the IHT.

Results: A total of $23 \mathrm{IHT}$ for head CT scans in 18 patients were analyzed. Traumatic brain injury $(n=7)$ was the leading cause of $\mathrm{ABI}$, followed by subarachnoid hemorrhage $(n=6)$ and intracerebral hemorrhage $(n=5)$. The analyzed microdialysis parameters in the brain tissue as in the subcutaneous tissue did not show significant changes between the pre-IHT and post-IHT period. In addition, we observed no significant increase in ICP or decrease in CPP and $\mathrm{PtiO}_{2}$ in the 8-h period after IHT.
\end{abstract}

Conclusions: While the occurrence of $\mathrm{AE}$ during $\mathrm{IHT}$ is a known risk factor for $\mathrm{ABI}$ patients, our results demonstrate that IHTs do not alter the brain tissue chemistry in a significant manner. This fact may help assess the risk for routine IHT more accurately.

Keywords: Acute brain injury, Intrahospital transport, Neuromonitoring, Cerebral microdialysis

\section{Introduction}

Acute brain injury (ABI) such as traumatic brain injury (TBI) and spontaneous intracerebral (ICH) or subarachnoid hemorrhage (SAH) is a life-threatening disease associated with high disability and mortality. Severely affected patients are at high risk for secondary brain injury (SBI) due to cerebral or systemic complications $[1,2]$. As patients with severe ABI are often admitted with a decreased level of consciousness or concomitant

*Correspondence: jan.kuechler@uksh.de

Department of Neurosurgery, University of Lübeck, Ratzeburger Allee 160, 23538 Lübeck, Germany respiratory complications, long-term sedation and mechanical ventilation are necessary in many cases.

In this setting, the neurological assessment is impossible and preventing SBI is particularly challenging. Thus, repeated computed tomography $(\mathrm{CT})$ scans and invasive neuromonitoring are indicated in these patients $[3,4]$. Given the use of portable CT scanners is not yet widely distributed [5], CT scans usually require an intrahospital transport (IHT) and risk for several adverse events (AE). In particular, respiratory complications and hemodynamic deteriorations are frequently reported in mechanically ventilated non-ABI patients during IHT [6]. Patients with $\mathrm{ABI}$ carry an additional risk to acquire IHT-related

\section{空


SBI as even short periods of hypotension or respiratory insufficiency may lead to reduced cerebral perfusion or cerebral hypoxia. Moreover, the supine position and routinely locked external ventricular drains during IHT contribute to the risk of high intracranial pressure (ICP) [7]. Accordingly, several previous studies reported transient ICP peaks during IHT of patients with ABI [8-11]. The potential gravity of these findings can hardly be judged without data about the functional outcome of these patients while also considering the lack of control groups. But in regard to the literature, it is well known that even transient ICP crisis in ABI patients is associated with severe alterations of cerebral metabolism [12] and subsequent neurological deterioration [13]. Whereas the previous studies deal with ICP and cerebral perfusion pressure (CPP), no data exist about changes in cerebral microdialysis during IHT in patients with severe ABI. The unique technique of cerebral microdialysis facilitates the sensitive detection of metabolic disturbances and early signs of SBI, even in case of normal ICP values [14]. Therefore, cerebral microdialysis might detect cerebral sequelae of IHT-related ICP peaks in ABI patients.

The purpose of this retrospective single-center study was to analyze the values of known microdialysis parameters of SBI before and after IHT in neurocritical patients with severe ABI.

\section{Patients and Methods \\ Patients}

All adult patients with ABI who were admitted to our single-center neurointensive care unit during a 4-year period were screened for intrahospital transports (IHTs). ABI was defined as spontaneous $\mathrm{SAH}, \mathrm{ICH}$, and TBI. Inclusion criteria were (1) need for at least one IHT for a follow-up CT scan during the first 7 days after admission; (2) continuous monitoring of ICP, brain tissue oxygenation pressure $\left(\mathrm{PtiO}_{2}\right)$, and cerebral microdialysis around IHT. Emergency IHTs in the setting of acute ICP crisis or neurological deterioration were excluded.

\section{Multimodality Neuromonitoring}

ICP was measured by a parenchymal pressure monitoring catheter $\left(\mathrm{Camino}^{\circledR}{ }^{\circledR}\right.$ Intracranial Pressure Monitoring Kit, Integra $\left.{ }^{\mathrm{TM}}\right)$ and $\mathrm{PtiO}_{2}$ by a brain tissue oxygen probe $\left(\mathrm{LICOX}^{\circledR}\right.$, Integra ${ }^{\mathrm{TM}}$ ). ICP and $\mathrm{PtiO}_{2}$ values were recorded hourly. Furthermore, patients were monitored with an intracerebral microdialysis catheter (70 Microdialysis Bolt Catheter, M Dialysis AB). All catheters were inserted through a single bolt system (LICOX $^{\circledR}$ Triple Lumen Introducer Kit, Integra $^{\mathrm{TM}}$ ) and were located in the frontal white matter of the most affected hemisphere. In addition, extracerebral microdialysis catheters (70 Microdialysis Bolt Catheter, M Dialysis AB) were placed subcutaneously. For bedside microdialysis, we used a 107 microdialysis pump (M Dialysis $\mathrm{AB}$ ) with a constant flow rate of $0.3 \mu \mathrm{l} / \mathrm{min}$ and the CMA 600 microdialysis analyzer (M Dialysis AB). Microdialysate samples were collected at a 60-min interval and analyzed immediately for the concentration of lactate, pyruvate, glutamate, and glycerol.

\section{Intrahospital Transports}

All IHT were executed in accordance with our own guideline for IHTs of mechanically ventilated patients. This includes a continuous monitoring of electrocardiography, blood pressure, and oxygenation (Infinity ${ }^{\circledR}$ Delta Monitor, Dräger Medical GmbH, Lübeck, Germany). An emergency transport ventilator $\left(\right.$ Oxylog $^{\circledR} 3000$ plus, Dräger Medical GmbH, Lübeck, Germany) was used in all cases, using the previous ventilation mode and the current ventilator settings. Deep sedation (Richmond Agitation-Sedation Scale -4 and -5) was achieved using continuous infusion of sedatives. ICP and $\mathrm{PtiO}_{2}$ probes were disconnected during IHT, while microdialysis pumps worked continuously during the IHT.

The transport team consisted of an intensive care nurse and an experienced intensive care physician. All patients were transported in their own bed with the head kept in midline position and elevated to $20^{\circ}-30^{\circ}$. The CT unit was located in the same building as the neurointensive care unit, but the use of an elevator was necessary. The average duration of each transport was approximately 20 min.

\section{Data Collection and Statistics}

Relevant patient demographics and diagnosis were retrospectively recorded. Since the intention of this study was to analyze the occurrence of IHT-related SBI, mean values of established cerebral microdialysis parameters around IHT were chosen as primary endpoints. To calculate the mean values, we selected a $16-\mathrm{h}$ period around IHT to ensure that all IHT-related changes were included.

The following hourly data were collected for all included IHT: microdialysis analysis of lactate, pyruvate, glycerol, and glutamate in cerebral and subcutaneous tissue, ICP, $\mathrm{PtiO}_{2}$, and CPP. Thresholds for microdialysis parameters were defined, in consideration of the most recent literature [11]. Limits of ICP, CPP, and $\mathrm{PtiO}_{2}$ were determined analog to current guidelines [5]. We only included parameters if more than 4 data points were present before and after the IHT. Otherwise, this IHT was eliminated from the analysis.

Data were analyzed using the software IBM $^{\circledR}$ SPSS $^{\circledR}$ (version 24.0). Results are presented as mean \pm standard deviation (figures) and median \pm interquartile range 
(tables). Nonparametric Mann-Whitney U test was used for comparing the results of the multimodal neuromonitoring between an 8-h period before and after IHT. Statistical significance was accepted at $p<0.05$.

\section{Results}

\section{Clinical and Demographic Data}

We analyzed a total of 23 IHT in 18 patients (11 males and 7 females) who met the inclusion criteria (Table 1). Median age of the patients was 43 years (range 32-55). The patients suffered from either one of the following neurosurgical diseases: TBI (7/18), SAH (6/18), and ICH (5/18). The patients were admitted with a median Glasgow Coma Scale of 5 (range 3-7). The intrahospital mortality rate was $0.22(4 / 18)$. With regards to functional outcome, the Modified Rankin Scale (mRS) value at hospital discharge was $4-5$ in 11 patients and mRS 3 in three patients (Table 1). No technical complication occurred during IHT. Moreover, no IHT-related acute pulmonary or hemodynamic deterioration or other adverse events were documented.

\section{Intracranial Monitoring (CPP, ICP, and $\mathrm{PtiO}_{2}$ )}

Hourly ICP and CPP values were available around all IHTs $(n=23) . \mathrm{PtiO}_{2}$ values were only available for 21 IHTs. The median values of ICP, CPP, and PtiO2 are given in Table 2. With regard to ICP and $\mathrm{PtiO}_{2}$, we found no significant differences between the pre-IHT and postIHT period $(p>0.05)$. Only CPP showed a significantly increase in the post-ITH period ( 74.9 vs. $77.6 \mathrm{mmHg}, p$ 0.027). Two patients showed a transient decrease in CPP $(<55 \mathrm{mmHg})$ in the pre-IHT period $(2 / 23)$ which was

\section{Table 1 Demographic data and clinical characteristics}

\begin{tabular}{ll} 
Number of patients $(n)$ & 18 \\
Median age [in years (IQR)] & $43[32-55]$ \\
Sex & \\
Male $[n(\%)]$ & $11[0.61]$ \\
Female $[n(\%)]$ & $7[0.39]$ \\
Diagnosis & \\
SAH $[n(\%)]$ & $6[0.33]$ \\
TBI $[n(\%)]$ & $7[0.39]$ \\
\hline ICH $[n(\%)]$ & $5[0.28]$ \\
Median GCS at admission $[n($ IQR) $]$ & $5[3-7]$ \\
Functional outcome (at discharge) & \\
\hline mRS 0-3 & $3[0.17]$ \\
mRS 4-5 & $11[0.61]$ \\
\hline mRS 6 & $4[0.22]$ \\
\hline
\end{tabular}

Demographic data and clinical characteristics of the included patients

ICH intracerebral hemorrhage, mRS modified Rankin Scale, SAH subarachnoid hemorrhage, $T B I$ traumatic brain injury
Table 2 Results of the intracranial multimodal neuromonitoring

\begin{tabular}{|c|c|c|c|}
\hline Parameter (brain) & $8 \mathrm{~h}$ before IHT & $8 \mathrm{~h}$ after IHT & $p$ value \\
\hline \multicolumn{4}{|l|}{ Glutamate } \\
\hline Median $(\mu \mathrm{mol})(\mathrm{IQR})$ & $10.1(1.6-18.3)$ & $9.8(1.4-15.5)$ & 0.651 \\
\hline No. $>10 \mu \mathrm{mol} / \mathrm{l}$ & $7 / 16$ & $8 / 16$ & \\
\hline \multicolumn{4}{|l|}{ Glycerol } \\
\hline Median ( $\mu \mathrm{mol})(\mathrm{IQR})$ & $91.9(48.2-195.0)$ & $159.5(42.2-220.2)$ & 0.081 \\
\hline No. $>150 \mu \mathrm{mol} / \mathrm{l}$ & $9 / 22$ & $11 / 22$ & \\
\hline \multicolumn{4}{|l|}{ Lactate } \\
\hline Median (mmol/lI) (IQR) & $3.31(2.23-4.47)$ & $3.62(1.92-4.59)$ & 0.462 \\
\hline No. $>4 \mathrm{mmol} / \mathrm{l}$ & $8 / 21$ & $11 / 21$ & \\
\hline \multicolumn{4}{|l|}{ Pyruvate } \\
\hline Median ( $\mu \mathrm{mol})(\mathrm{IQR})$ & $92.3(71.3-164.8)$ & $97.0(74.4-160.8)$ & 0.578 \\
\hline No. $<50 \mu \mathrm{mol} / \mathrm{l}$ & $4 / 20$ & $4 / 20$ & \\
\hline \multicolumn{4}{|l|}{ LPR } \\
\hline Median (IQR) & $30.0(19.1-39.4)$ & $29.7(20.2-35.9)$ & 0.782 \\
\hline$L P R>40$ & $8 / 20$ & $6 / 20$ & \\
\hline$L P R>25$ & $13 / 20$ & $14 / 20$ & \\
\hline \multicolumn{4}{|l|}{ ICP } \\
\hline Median (IQR) & $14.0(7.0-18.0)$ & $12.5(7.8-16.0)$ & 0.238 \\
\hline No. $>20 \mathrm{mmHg}$ & $6 / 22$ & $4 / 22$ & \\
\hline \multicolumn{4}{|l|}{ CPP } \\
\hline Median (IQR) & $75.0(67.0-83.0)$ & $77.0(70.8-84.0)$ & $0.027^{*}$ \\
\hline $\mathrm{No} .<55 \mathrm{mmHg}$ & $2 / 23$ & $0 / 23$ & \\
\hline \multicolumn{4}{|l|}{$\mathrm{PTiO}_{2}$} \\
\hline Median (IQR) & $27.6(20.7-40.0)$ & $31.4(22.1-42.0)$ & 0.369 \\
\hline No. $<10 \mathrm{mmHg}$ & $2 / 21$ & $0 / 21$ & \\
\hline
\end{tabular}

For each parameter, the number of patients whose values exceeded the physiological thresholds is shown. Data are presented as median and interquartile range (IQR). Statistical significance was accepted at $p<0.05(*)$

$C P P$ cerebral perfusion pressure, $I C P$ intracranial pressure, $I H T$ intrahospital transport, IQR interquartile range, $L P R$ lactate/pyruvate ratio

not present in the post-IHT periods. Six patients showed intracranial hypertension (ICP $>20 \mathrm{mmHg}$ ) in the preIHT period (6/23 IHT), while only 4 patients showed a transient ICP elevation in the post-IHT period. None of these patients had ICP values over $25 \mathrm{mmHg}$. Figure 1 shows the course of the analyzed parameters during the 8-h period before and after the IHT.

\section{Brain Tissue Metabolism}

The results of brain microdialysis are given in Table 2 . Data for brain lactate were available in 21/23 IHT, for brain pyruvate and lactate/pyruvate ratio (LPR) in 20/23 IHT, for brain glycerol in $22 / 23$ IHT, and for brain glutamate in 17/23 IHT. Figure 2 shows the course of the analyzed parameters during the 8 -h period before and after the IHT. We found no significant changes in the analyzed microdialysis parameters between the 8 -h period before 

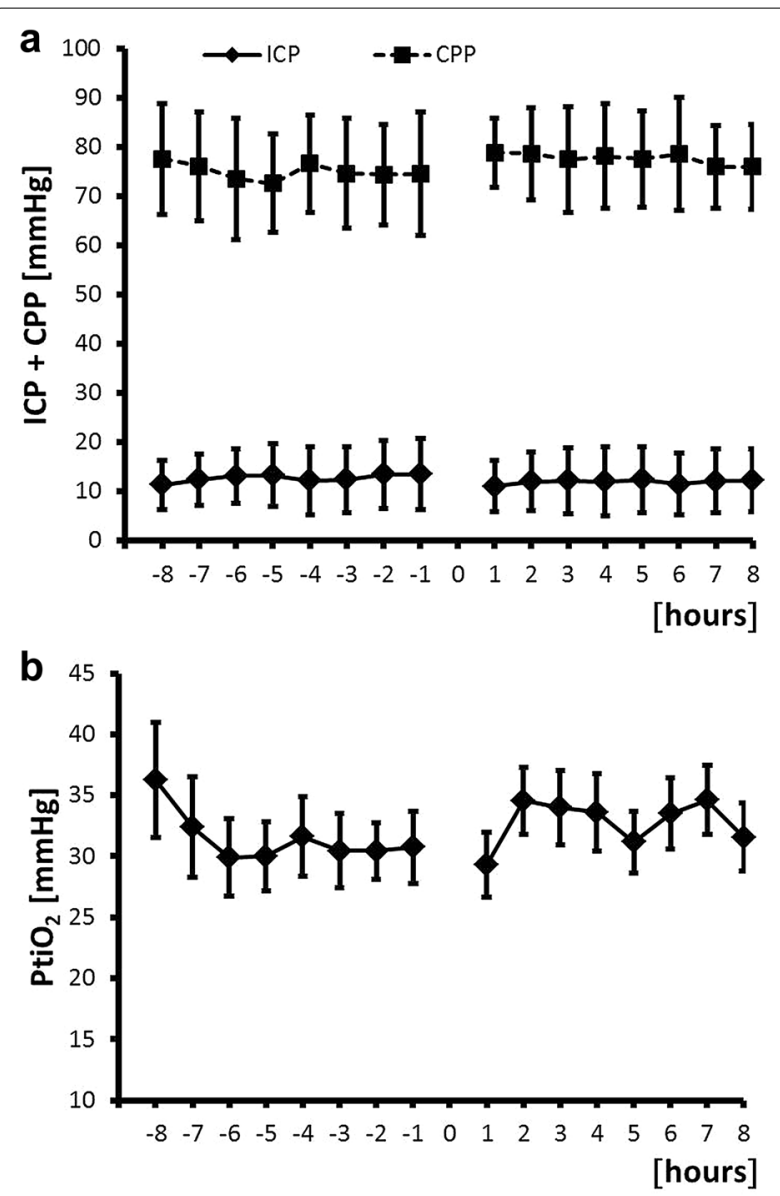

Fig. 1 Hourly values of intracranial pressure (ICP), cerebral perfusion pressure (CPP) (a) and brain tissue oxygenation $\left(\mathrm{PtiO}_{2}\right)(\mathbf{b}) 8 \mathrm{~h}$ before and after the intrahospital transport (ITH). Data are presented as mean and standard deviation (SD)

and after the IHT (Table 2). With regard to the heterogeneous brain pathologies, the subgroup analysis (TBI, $\mathrm{SAH}$, and $\mathrm{ICH}$ ) showed no significant changes between the 8-h period before and after the IHT as well. In the ICH patients, glutamate and glycerol showed a certain trend toward higher values after the IHT (not statistically significant). However, the metabolic parameters showed no concomitant changes in this direction (Table 3).

In a significant proportion of IHT, the given thresholds of analyzed brain parameters were exceeded. But we could not find an accumulation of any analyzed parameter in the post-IHT course (Table 2).

\section{Subcutaneous Tissue Metabolism}

The same parameters which were analyzed in the brain tissue were also compiled in the subcutaneous tissue. The tissue values of lactate, pyruvate, and LPR could be calculated for 19/23 IHT, whereas glutamate values were available from 17/23 IHT and glycerol values from 20/23
IHT. None of the subcutaneous parameters differed significantly between the pre-IHT and post-IHT period (Table 4). The course of the analyzed parameters during the 8 -h period before and after the IHT is shown in Fig. 3.

\section{Discussion}

In the present study, we demonstrate that IHTs do not compromise the brain tissue metabolism of mechanically ventilated patients with $A B I$ in a significant matter. This was unexpected as various $\mathrm{AE}$ are frequently (incidence between 0.37 and 0.60 ) observed in mechanically ventilated ICU patients [15-18]. Different patient-related events are summarized under the term $\mathrm{AE}$, including oxygen desaturation, hemodynamic instability, and accidental removal of central venous catheter. All AE have the potential to cause relevant physiological alterations, which might harm the patients and lead to longer ICU stay and increased mortality $[16,18]$. Thus, numerous studies and guidelines deal with opportunities to lower the IHT-related risk for AE [19-22].

Minor data exist about the impact of IHT in mechanically ventilated brain-injured patients. Acute brain injury reduces the intracranial compliance and inhibits the physiological mechanisms of cerebral autoregulation. In this setting, the brain is highly vulnerable to physiological derangements like hypercarbia, hypoxia, or hypotension. As in other intensive care procedures like tracheostomy, prone positioning, or bronchoscopy, IHT-related AE and subsequent alteration of hemodynamic or respiratory parameters jeopardize the ABI patient particularly and may provoke SBI [23-25]. Recent studies observed a high incidence (up to 1.0) of ICP increases and consecutive CPP decreases during IHT in neurocritical patients [7, 9-11]. Uncertainty prevails regarding the consequences of this transient increase as no studies provide information about IHT-related deteriorations in regard to the functional outcome. But it can be assumed that even transient ICP crises may worsen the outcome [26-28]. In accordance with the previous data, we could rule out any significant disturbances of ICP and CPP in the post-IHT periods.

As the patients were disconnected from the ICP monitor during IHT, no ICP and CPP values were available in this critical phase. Nevertheless, we have to expect that a significant proportion of our patients had transient ICP elevations and CPP drops.

The use of cerebral microdialysis during IHT has yet not been published, although this technique provides a valuable opportunity to predict secondary ischemic events in ABI patients [29-31]. In our study, we observed exceedances of the given thresholds for all metabolic parameters in both periods in nearly half of the IHT, a fact that demonstrates the severity of the brain injuries 

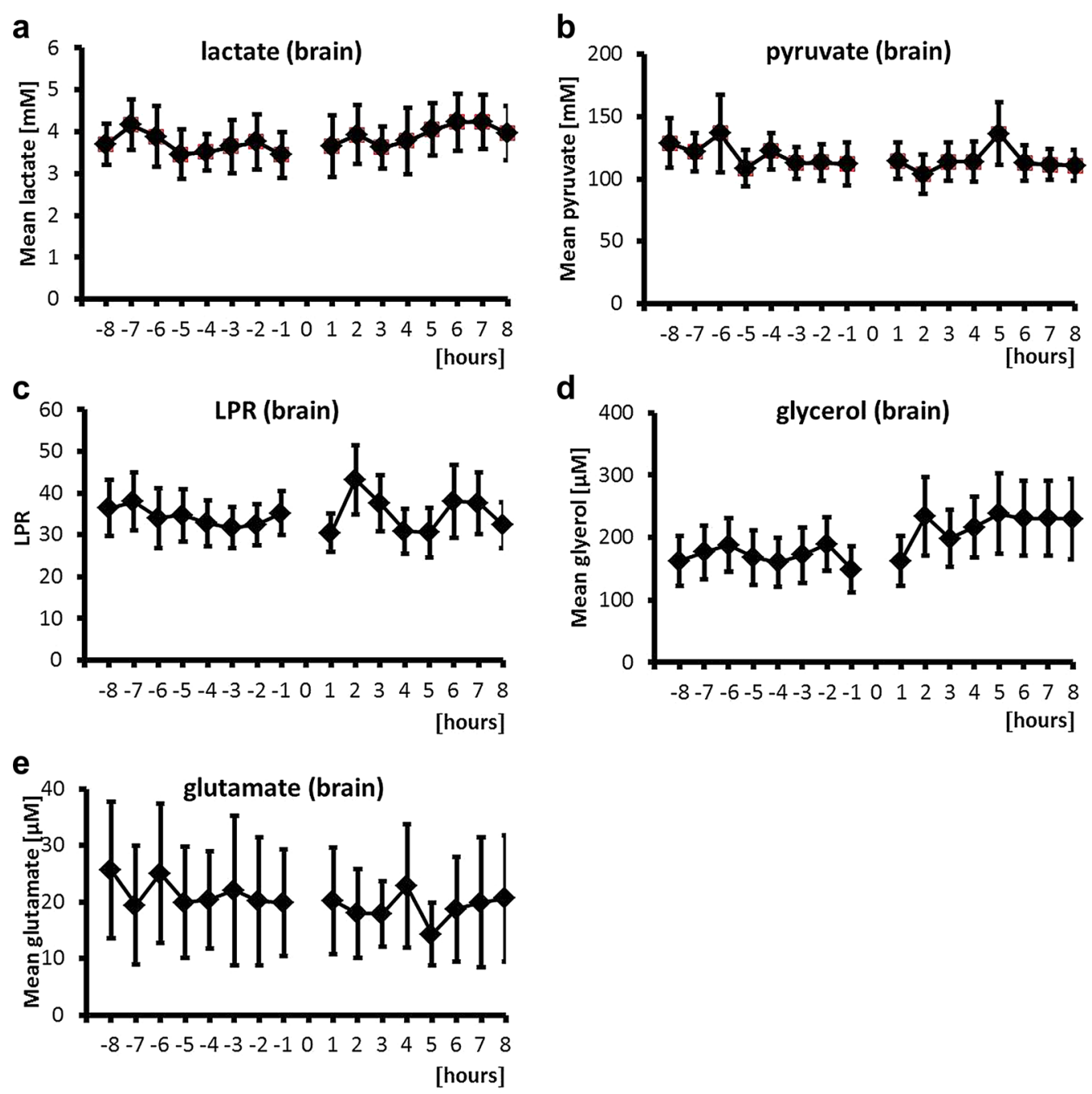

Fig. 2 Hourly values of cerebral lactate (a), cerebral pyruvate (b), cerebral lactate/pyruvate ratio (c), cerebral glycerol (d) and cerebral glutamate (e) $8 \mathrm{~h}$ before and after the intrahospital transport (ITH). Data are presented as mean and standard deviation (SD)

of the included patients [30]. In particular, the high values of LPR indicate that a significant proportion of these patients suffer from severe disturbances in brain tissue metabolism even before IHT. As expected in these patients, the analysis of functional outcome showed a high rate of unfavorable outcome and mortality.

Nevertheless, our results from the cerebral microdialysis show that IHT did not provoke a metabolic crisis as the mean values of lactate, pyruvate, and LPR did not differ significantly between the pre-IHT and post-IHT course.

Furthermore, we analyzed the neurotransmitter glutamate, whose excess release is associated with ischemic events [32,33]. A significant change in mean glutamate in the brain tissue could not be detected in our patients. The onset of IHT-related ischemic events in our patients therefore seems to be improbable.
The analysis of cerebral glycerol, a marker of cell membrane breakdown [34], revealed at least a slight (but not significant) increase in the post-IHT period. As brain tissue levels of glycerol are known to be of minor specificity, one should interpret the results in relation to non-cerebral values [35]. In the subcutaneous tissue, we did not find a trend toward higher levels of glycerol. These results suggest a brain-specific increase in glycerol. But the missing significance of this effect and furthermore the absence of concomitant alterations in the brain metabolism and stable brain tissue glutamate levels put these findings into perspective.

Overall, the microdialysis results of the subcutaneous tissue showed steady values of all analyzed parameters, indicating that IHTs do not lead to relevant physiologic alterations in brain tissue and subcutaneous chemistry. 
Table 3 Subgroup analysis of cerebral microdialysis

\begin{tabular}{clll}
\hline Parameter & Subgroups & $\mathbf{8} \mathbf{~}$ before IHT & $\mathbf{8} \mathbf{~}$ after IHT \\
\hline Glutamate $(\mu \mathrm{mol})$ & TBI & $9.3(2.0-16.3)$ & $9.9(4.5-15.3)$ \\
median (IQR) & SAH & $2.0(0.7-10.0)$ & $0.6(0.4-3.4)$ \\
& ICH & $2.9(1.6-154.7)$ & $4.0(1.7-122.3)$ \\
Glycerol ( $\mu$ mol) & TBI & $57.2(32.7-125.0)$ & $60.6(36.9-151.5)$ \\
median (IQR) & SAH & $125.1(80.1-525.2)$ & $157.1(74.3-803.5)$ \\
& ICH & $150.9(59.0-264.8)$ & $201.0(66.1-248.2)$ \\
Lactate (mmol/I) & TBI & $2.53(2.03-2.71)$ & $2.94(1.56-3.88)$ \\
median (IQR) & SAH & $3.21(1.66-5.28)$ & $3.19(1.73-7.74)$ \\
& ICH & $3.72(2.73-8.50)$ & $4.0(3.16-7.60)$ \\
Pyruvate ( $\mu$ mol) & TBI & $113.1(80.1-170.3)$ & $116.0(83.8-164.7)$ \\
median (IQR) & SAH & $55.7(45.9-90.7)$ & $67.1(29.1-78.6)$ \\
& ICH & $107.6(83.3-211.7)$ & $110.9(78.4-188.5)$ \\
LPR median (IQR) & TBI & $19.8(17.5-26.5)$ & $21.9(18.1-25.9)$ \\
& SAH & $32.2(21.5-56.0)$ & $34.3(20.2-87.6)$ \\
& ICH & $36.4(28.2-41.4)$ & $34.1(27.2-42.5)$
\end{tabular}

Data are presented as median and interquartile range (IQR). There was no statistical significance $(p>0.05)$

$I C H$ intracerebral hemorrhage, IHT intrahospital transport, IQR interquartile range, $L P R$ lactate/pyruvate ratio, $S A H$ subarachnoid hemorrhage, TBI traumatic brain injury

However, the findings that IHTs do not cause metabolic brain tissue alterations in our patients should not lead to the suggestion that IHT might be harmless in patients with ABI. Transient rises of ICP and occurrence of AE might seriously jeopardize the patients in a manner that cannot be detected by cerebral microdialysis.

In sum, the risks of IHT are well known, but one should not overestimate the risk for $\mathrm{ABI}$ patients in the decisionmaking about routine $\mathrm{CT}$ scanning. The discussion about this kind of imaging is quite conflicting as some authors propagate repeated $\mathrm{CT}$ scanning $[3,36]$, while others are skeptical about its value $[37,38]$. Nevertheless, it has been proven that carefully preparing IHT and the use of trained staff enhance patient safety $[19,22]$.

The clear indication for emergency CT scans is undisputed; hence, we have excluded these scans. Moreover, emergency CT scans are mainly performed during the first hours after onset of $\mathrm{ABI}$ and at this stage data from cerebral microdialysis are not available.

Our study has some limitations to be considered. The retrospective study design caries some selection bias, and the number of IHTs $(n=23)$ appears small. However, we can demonstrate results from cerebral microdialysis during IHT for the first time and it is particularly challenging to recruit more data since the routine use of cerebral microdialysis in neurocritical care is very complex and thus restricted to selected patients.

Cerebral microdialysis is a focal technique, which is used in the most affected hemisphere. No information about the less affected hemisphere or distant regions in the measured hemisphere was collected. Nevertheless, cerebral microdialysis is well established despite these known limitations [35]. Another limitation is the lack of intracranial data (CPP and ICP) during the IHT, although routinely neuromonitoring during IHT is feasible using portable systems. Further investigations about this issue should include these important data as it would be of significant interest to correlate transient ICP increases with the values from the cerebral microdialysis.

In addition, AE were not documented systematically; thus, we can only speculate about the presence of $\mathrm{AE}$ during our IHTs in accordance with the previously published rates.

\section{Conclusions}

IHT is a known risk factor for ABI patients, causing serious $\mathrm{AE}$ and transient ICP elevations in a relevant proportion of these patients. Nevertheless, we could

Table 4 Results of subcutaneous microdialysis

\begin{tabular}{|c|c|c|c|}
\hline Parameter (subcutaneous tissue) & $8 \mathrm{~h}$ before IHT & $8 \mathrm{~h}$ after IHT & $p$ value \\
\hline \multicolumn{4}{|l|}{ Glutamate } \\
\hline Median ( $\mu \mathrm{mol})(\mathrm{IQR})$ & $2.3(0.9-7.3)$ & $1.8(1.0-6.5)$ & 0.856 \\
\hline \multicolumn{4}{|l|}{ Glycerol } \\
\hline Median $(\mu \mathrm{mol})(\mathrm{IQR})$ & $247.6(131.2-401.2)$ & $206.4(124.7-380.3)$ & 0.958 \\
\hline \multicolumn{4}{|l|}{ Lactate } \\
\hline Median (mmol/I) (IQR) & $1.27(0.96-1.86)$ & $1.32(0.99-1.90)$ & 0.775 \\
\hline \multicolumn{4}{|l|}{ Pyruvate } \\
\hline Median $(\mu \mathrm{mol})(\mathrm{IQR})$ & $120.8(73.1-140.0)$ & $109.7(66.8-141.7)$ & 0.292 \\
\hline \multicolumn{4}{|l|}{ LPR } \\
\hline Median (IQR) & $12.2(10.5-16.2)$ & $13.4(10.0-18.9)$ & 0.218 \\
\hline
\end{tabular}

Data are presented as median and interquartile range (IQR). Statistical significance was accepted at $p<0.05$

$I H T$ intrahospital transport, IQR interquartile range, $L P R$ lactate/pyruvate ratio 

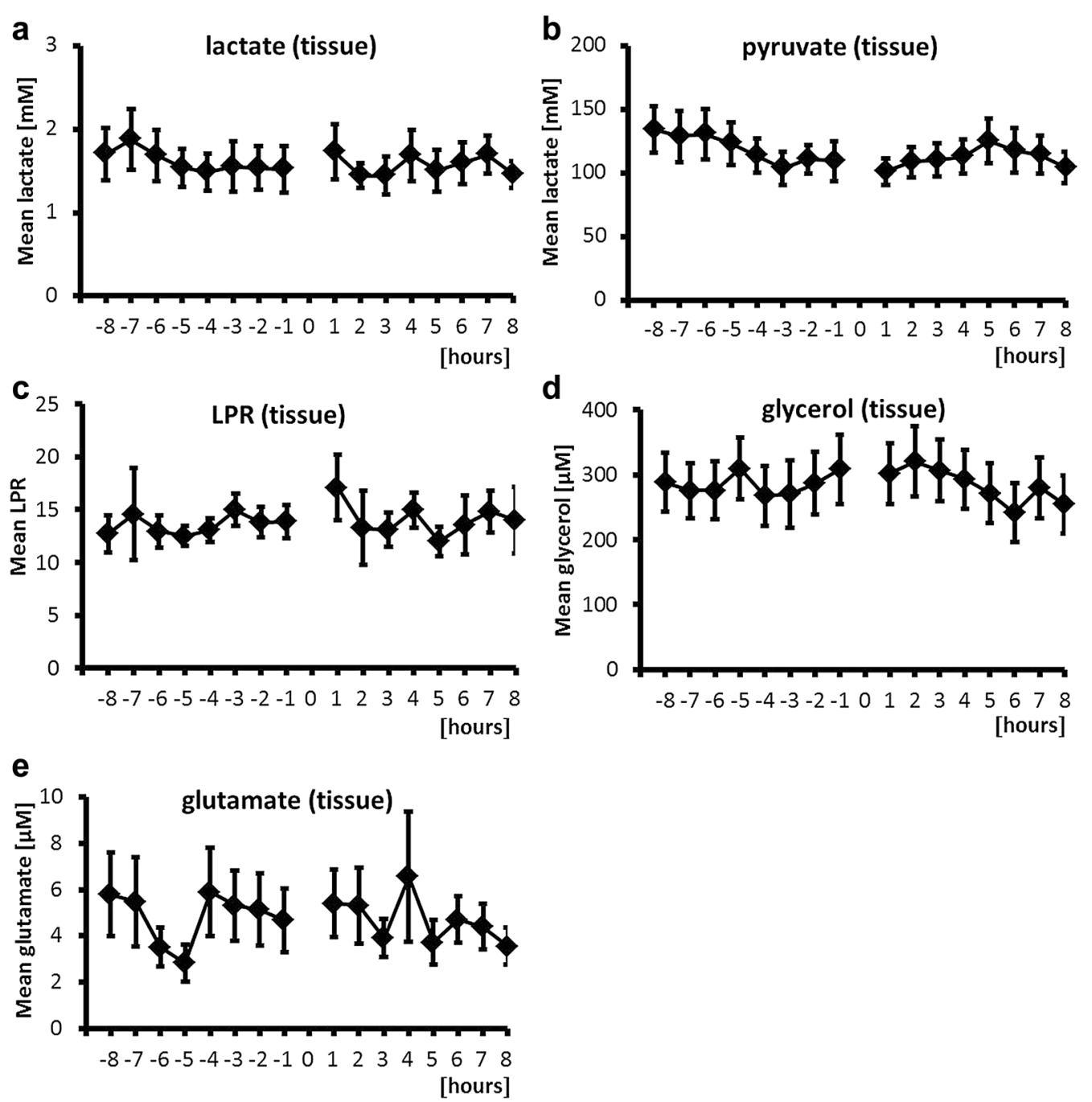

Fig. 3 Hourly values of lactate (a), pyruvate (b), lactate/pyruvate ratio (c), glycerol (d) and glutamate (e) in the subcutaneous tissue $8 \mathrm{~h}$ before and after the intrahospital transport (ITH). Data are presented as mean and standard deviation (SD)

demonstrate that IHTs do not alter the brain tissue chemistry. This fact may allow a more accurate risk assessment for routine follow-up CT scans. Still, critical decisionmaking for repeated CT scanning and an evidence-based standard of care for IHT are still of great value for ABI patients.

\section{Author Contribution}

JK contributed to conception and design of the study, statistical analysis and interpretation of data, drafting of the article, and final approval of the version to be published. FT contributed to acquisition of data, revision of the article for important intellectual content, and final approval of the version to be published. ES contributed to acquisition of data, drafting and revision of the article, and final approval of the version to be published. JG and VMT contributed to conception and study design, revision of the article for important intellectual content, and final approval of the version to be published. CD contributed to conception and design of the study, analysis and interpretation of data, drafting of the article, and final approval of the version to be published.

Source of support

The authors received no financial support for this study.

Compliance with Ethical Standards

Conflict of interest

The authors declare that they have no conflict of interest.

\section{Ethical Approval}

The study has been approved by the institutional ethics committee. For this type of retrospective study, formal consent is not required.

Published online: 10 September 2018 


\section{References}

1. Jeremitsky E, Omert L, Dunham CM, Protetch J, Rodriguez A. Harbingers of poor outcome the day after severe brain injury: hypothermia, hypoxia, and hypoperfusion. J Trauma. 2003;54:312-9.

2. Unterberg AW, Stover J, Kress B, Kiening KL. Edema and brain trauma. Neuroscience. 2004;129:1021-9.

3. Brown CV, Zada G, Salim A, et al. Indications for routine repeat head computed tomography (CT) stratified by severity of traumatic brain injury. J Trauma. 2007:62:1339-44

4. Tasneem N, Samaniego EA, Pieper C, et al. Brain multimodality monitoring: a new tool in neurocritical care of comatose patients. Crit Care Res Pract. 2017;2017:6097265.

5. John S, Stock S, Cerejo R, et al. Brain imaging using mobile CT: current status and future prospects. J Neuroimaging. 2016;26:5-15.

6. Evans A, Winslow EH. Oxygen saturation and hemodynamic response in critically ill, mechanically ventilated adults during intrahospital transport. Am J Crit Care. 1995:4:106-11.

7. Chaikittisilpa N, Lele AV, Lyons VH, et al. Risks of routinely clamping external ventricular drains for intrahospital transport in neurocritically ill cerebrovascular patients. Neurocrit Care. 2017;26:196-204.

8. Andrews PJ, Piper IR, Dearden NM, Miller JD. Secondary insults during intrahospital transport of head-injured patients. Lancet (London, England). 1990;335:327-30

9. Kleffmann J, Pahl R, Deinsberger W, Ferbert A, Roth C. Intracranial pressure changes during intrahospital transports of neurocritically ill patients. Neurocrit Care. 2016;25:440-5.

10. Martin M, Cook F, Lobo D, et al. Secondary insults and adverse events during intrahospital transport of severe traumatic brain-injured patients. Neurocrit Care. 2017:26:87-95.

11. Trofimov A, Kalentiev G, Yuriev M, Pavlov V, Grigoryeva V. Intrahospital transfer of patients with traumatic brain injury: increase in intracranial pressure. Acta Neurochir. 2016;122:125-7.

12. Nagel A, Graetz D, Schink T, et al. Relevance of intracranial hypertension for cerebral metabolism in aneurysmal subarachnoid hemorrhage. Clinical article. J Neurosurg. 2009;111:94-101.

13. Ryttlefors M, Howells T, Nilsson P, Ronne-Engstrom E, Enblad P. Secondary insults in subarachnoid hemorrhage: occurrence and impact on outcome and clinical deterioration. Neurosurgery. 2007:61:704-14.

14. Chen HI, Stiefel MF, Oddo M, et al. Detection of cerebral compromise with multimodality monitoring in patients with subarachnoid hemorrhage. Neurosurgery. 2011;69:53-63.

15. Bergman LM, Pettersson ME, Chaboyer WP, Carlstrom ED, Ringdal ML. Safety hazards during intrahospital transport: a prospective observational study. Crit Care Med. 2017;45:e1043-9.

16. Gimenez FMP, de Camargo WHB, Gomes ACB, et al. Analysis of adverse events during intrahospital transportation of critically ill patients. Crit Care Res Pract. 2017;2017:6847124.

17. Parmentier-Decrucq E, Poissy J, Favory R, et al. Adverse events during intrahospital transport of critically ill patients: incidence and risk factors. Ann Intensive Care. 2013;3:10

18. Schwebel C, Clec'h C, Magne S, et al. Safety of intrahospital transport in ventilated critically ill patients: a multicenter cohort study*. Crit Care Med. 2013:41:1919-28.

19. Brunsveld-Reinders AH, Arbous MS, Kuiper SG, de Jonge E. A comprehensive method to develop a checklist to increase safety of intra-hospital transport of critically ill patients. Crit Care (London, England). 2015;19:214.

20. Donovan AL, Aldrich JM, Gross AK, et al. Interprofessional care and teamwork in the ICU Crit Care Med. 2018:46:980-90.
21. Fanara B, Manzon C, Barbot O, Desmettre T, Capellier G. Recommendations for the intra-hospital transport of critically ill patients. Crit Care (London, England). 2010;14:R87.

22. Warren J, Fromm RE Jr, Orr RA, Rotello LC, Horst HM. Guidelines for the inter- and intrahospital transport of critically ill patients. Crit Care Med. 2004;32:256-62.

23. Kerwin AJ, Croce MA, Timmons SD, et al. Effects of fiberoptic bronchoscopy on intracranial pressure in patients with brain injury: a prospective clinical study. J Trauma. 2000:48:878-82.

24. Küchler J, Wojak J, Abusamha A, et al. Analysis of extracellular brain chemistry during percutaneous dilational tracheostomy: a retrospective study of 19 patients. Clin Neurol Neurosurg. 2017;159:1-5.

25. Reinprecht A, Greher M, Wolfsberger S, et al. Prone position in subarachnoid hemorrhage patients with acute respiratory distress syndrome: effects on cerebral tissue oxygenation and intracranial pressure. Crit Care Med. 2003:31:1831-8.

26. Balestreri M, Czosnyka M, Hutchinson P, et al. Impact of intracranial pres sure and cerebral perfusion pressure on severe disability and mortality after head injury. Neurocrit Care. 2006;4:8-13.

27. Chesnut RM, Marshall LF, Klauber MR, et al. The role of secondary brain injury in determining outcome from severe head injury. J Trauma. 1993;34:216-22.

28. Heuer GG, Smith MJ, Elliott JP, Winn HR, LeRoux PD. Relationship between intracranial pressure and other clinical variables in patients with aneurysmal subarachnoid hemorrhage. J Neurosurg. 2004;101:408-16.

29. Adamides AA, Rosenfeldt FL, Winter CD, et al. Brain tissue lactate elevations predict episodes of intracranial hypertension in patients with traumatic brain injury. J Am Coll Surg. 2009;209:531-9.

30. Sarrafzadeh AS, Sakowitz OW, Kiening KL, et al. Bedside microdialysis: a tool to monitor cerebral metabolism in subarachnoid hemorrhage patients? Crit Care Med. 2002;30:1062-70.

31. Timofeev I, Carpenter KL, Nortje J, et al. Cerebral extracellular chemistry and outcome following traumatic brain injury: a microdialysis study of 223 patients. Brain. 2011;134:484-94.

32. Enblad P, Valtysson J, Andersson J, et al. Simultaneous intracerebral microdialysis and positron emission tomography in the detection of ischemia in patients with subarachnoid hemorrhage. J Cereb Blood Flow Metab. 1996;16:637-44.

33. Hlatky R, Valadka AB, Goodman JC, Contant CF, Robertson CS. Patterns of energy substrates during ischemia measured in the brain by microdialysis. J Neurotrauma. 2004;21:894-906.

34. Clausen $T$, Alves $\mathrm{OL}$, Reinert $\mathrm{M}$, et al. Association between elevated brain tissue glycerol levels and poor outcome following severe traumatic brain injury. J Neurosurg. 2005;103:233-8.

35. Hutchinson PJ, Jalloh I, Helmy A, et al. Consensus statement from the 2014 international microdialysis forum. Intensive Care Med. 2014:41:1517-28.

36. Park HK, Joo WI, Chough CK, et al. The clinical efficacy of repeat brain computed tomography in patients with traumatic intracranial haemorrhage within 24 hours after blunt head injury. Br J Neurosurg. 2009;23:617-21.

37. Chao A, Pearl J, Perdue P, et al. Utility of routine serial computed tomography for blunt intracranial injury. J Trauma. 2001;51:870-5.

38. Kaups KL, Davis JW, Parks SN. Routinely repeated computed tomography after blunt head trauma: does it benefit patients? The Journal of trauma. 2004;56:475-80. 